\title{
STUDY OF UPPER LIMB PERIPHERAL NERVE PATHOLOGIES WITH SPECIAL EMPHASIS ON QUICK DASH SCORE AND SELECTED ELECTROMYOGRAPHIC PARAMETERS
}

\author{
Archana Verma1, Sachin Verma², Sonia Moses ${ }^{3}$, Rajkumar Mathur ${ }^{4}$, Lukesh Patil5, Siddharth Saraf6, Abhishek Verma ${ }^{7}$, Sharad Gova ${ }^{8}$
}

${ }^{1}$ Assistant Professor, (Neurology Unit) Department of Medicine, MGM M.C. Indore.

${ }^{2}$ Assistant Professor, Plastic and Reconstructive Surgeon, Department of Surgery, MGM M.C. Indore.

${ }^{3}$ Associate Professor, Department of Surgery, MGM M.C. Indore.

${ }^{4}$ Professor and Head, Department of Surgery, MGM M.C. Indore.

${ }^{5}$ Resident, Department of Surgery, MGM M.C. Indore.

${ }^{6}$ Resident, Department of Surgery, MGM M.C. Indore.

${ }^{7}$ Resident, Department of Surgery, MGM M.C. Indore.

${ }^{8}$ Resident, Department of Surgery, MGM M.C. Indore.

\section{BACKGROUND}

ABSTRACT

Clinical disability or inability to use full function of upper limb and EMG can be a guide to assess probability of severity of pathological damage. Pathologies like neuropraxia, axonotmesis and neurotmesis have varied disability presentation and EMG findings. Hence, disability scores and EMG can correlate well with peripheral nerve pathologies.

The purpose of this study is evaluation of peripheral nerve pathologies using disability score and electromyographic (EMG) findings.

\section{MATERIALS AND METHODS}

Study design was hospital-based cross-sectional study, which was conducted in outpatient medical and surgical department of MY Hospital, Indore, in patients of upper limb peripheral nerve pathologies with intention of identifying the selected epidemiological variables along with measurement of quick DASH (Disabilities of the Arm, Shoulder and Hand score) and analysing the electromyographic findings. Study was conducted over a period of one year from January 2015 to December 2015.

\section{RESULTS}

There were 51 patients (mean age 36; SD, 11.7 years) with peripheral nerve pathologies $(n=39)$ and traumatic injuries ( $n=12$ ). Female-to-male ratio was 2.18: 1. Mean quick DASH score was 61.35 (SD, 20.5) of 100. For traumatic patients mean quick DASH score was 83.25 (SD, 13.13) and for non-traumatic patients it was 57.41 (SD, 14.65). Electromyographic parameter of voluntary muscle activity and recruitment were absent in all of the twelve traumatic injury patients and it was present in other thirty-nine non-traumatic neuropathies. Electromyographic finding of spontaneous potential was observed in all the 51 patients.

\section{CONCLUSION}

High quick DASH scores are found in traumatic injury patients. In non-traumatic neuropathies, the quick DASH scores are quite disabling but not that high. Electromyographic findings in traumatic injuries are suggestive of neurotmesis. Finding of spontaneous activity in all the patients suggest active denervation (axonotmesis or neurotmesis) and it warrants aggressive treatment.

\section{KEYWORDS}

Quick DASH Score, Peripheral Nerve Pathology, Electromyography.

HOW TO CITE THIS ARTICLE: Verma A, Verma S, Moses S, et al. Study of upper limb peripheral nerve pathologies with special emphasis on quick DASH score and selected electromyographic parameters. J. Evolution Med. Dent. Sci. 2018;7(04):499-503, DOI: $10.14260 /$ jemds/2018/111

\section{BACKGROUND}

Peripheral neuropathy (PN) is a common disorder and presents as diagnostic and therapeutic challenge to physicians and neurologists. ${ }^{1}$ In epidemiological studies from India from various regions the overall prevalence of PN varied from 5 to 2400 per 10,000 populations in various community studies. ${ }^{1}$ Various causes of neuropathy include diabetes mellitus and other metabolic causes, toxins, various infections and inflammations, tumour, nutritional deficiencies and traumatic injuries.

'Financial or Other Competing Interest': None.

Submission 11-11-2017, Peer Review 06-01-2018,

Acceptance 13-01-2018, Published 22-01-2018.

Corresponding Author:

Dr. Sachin Verma

8, Rajbada Chowk, Indore-452001.

E-mail: drarchanaverma1@gmail.com

DOI: $10.14260 /$ jemds $/ 2018 / 111$

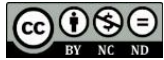

Patients of severe peripheral neuropathy experience considerable disability and pain. Quick DASH score is a useful tool for assessing upper limb function, pain and quality of life in such patients. Extent of pathological damage can be easily ascertained by electromyography. Electrodiagnostic severity based on latency does not correlate well with quick DASH score. $^{2}$ Objective of study is grading the severity of quick DASH score and correlating it with various pathologies of neuropathy.

\section{MATERIALS AND METHODS}

Study design is hospital-based cross-sectional study. Fifty one upper limb peripheral neuropathy patients, who had already undergone electrodiagnostic evaluation and reported to medical and surgical outpatient departments from January 2015 to December 2015 were included in the study. Inclusion criteria consisted of patients already enrolled in outpatient department for peripheral neuropathy (traumatic and non- 
traumatic) both with findings of electrodiagnostic reports and response of quick DASH score. Patients with negative or incomplete electrodiagnostic study were excluded from the study. Epidemiological variables like age and sex were noted. Response to standard quick DASH questionnaires was jotted down. Electrodiagnostic report analysed and following parameters were recorded-

1. Presence or absence of voluntary muscle contraction.

2. Presence or absence of recruitment.

3. Presence or absence of spontaneous potential.

Nerve conduction study parameters like latency and conduction velocity were not included in the study. Data was analysed using appropriate statistical method. Confidentiality of patients was not revealed at any point of study.

\section{RESULTS}

1. Fifty one patients were recruited in the study group out of many peripheral neuropathy patients reported. Small number of patients is because of fixed inclusion criteria.

2. Mean age of studied patients was 36 years (SD, 11.7 years). Youngest patient was of 15 years old and eldest was of 55 years old (Table 1 ).

3. Out of 51 patients, 35 patients were females and 16 patients were male. Female-to-male ratio was 2.18: 1 (Table 1).

4. Total number of non-traumatic upper limb neuropathy patients were 39 and traumatic peripheral neuropathy patients were 12 in number (Table 2).

5. $62.74 \%$ patients had quick DASH score of range $50-80$, designated by authors as of moderate severity (Table 3).

6. Mean quick DASH score of disability assessment was 61.35 (SD, 20.5) out of 100 (Table 4).

7. Mean quick DASH score for traumatic patients was 83.25 (SD, 13.13) (Table 4).

8. Mean quick DASH score for non-traumatic patients was 57.41 (SD, 14.65) (Table 4).

9. Voluntary muscle contraction (Needle Electromyography finding) was present in 39 non-traumatic peripheral neuropathy patients and absent in 12 traumatic peripheral neuropathy patients (Table 4).

10. Recruitment pattern (Needle Electromyography finding) of muscle unit supplied by pathological nerve was present in 39 non-traumatic peripheral neuropathy patients and not obtainable in 12 traumatic injury neuropathy patients (Table 4).

11. Finding of spontaneous potentials as fibrillations and fasciculations was observed in all the 51 patients, (Table 4).

\begin{tabular}{|c|c|c|c|c|c|c|}
\hline \multirow{2}{*}{ Age Group } & \multicolumn{2}{|c|}{$\begin{array}{c}\text { Female } \\
\mathbf{3 5}\end{array}$} & \multicolumn{2}{c|}{$\begin{array}{c}\text { Male } \\
\mathbf{1 6}\end{array}$} & \multicolumn{2}{|c|}{ Total } \\
\cline { 2 - 7 } & No. & $\mathbf{\%}$ & No. & $\mathbf{\%}$ & No. & $\mathbf{\%}$ \\
\hline 10-20 years & 2 & 3.9 & 1 & 1.96 & 3 & 5.88 \\
\hline $20-30$ years & 10 & 19.6 & 8 & 15.6 & 18 & 35.29 \\
\hline $30-40$ years & 11 & 21.5 & 4 & 7.84 & 15 & 29.41 \\
\hline 40-50 years & 2 & 3.9 & 1 & 1.96 & 3 & 5.88 \\
\hline$>50$ years & 10 & 19.6 & 2 & 3.9 & 12 & 23.5 \\
\hline
\end{tabular}

\begin{tabular}{|c|c|c|}
\hline \multirow{2}{*}{ Mode of Onset } & Total \\
\cline { 2 - 3 } & No. & \% \\
\hline Post-traumatic injury & 12 & 23.5 \\
\hline Non-traumatic patients & 39 & 76.47 \\
\hline \multicolumn{2}{|c|}{ Table 2. Distribution of Patients according to Mode of } \\
Onset (n= 51) \\
\hline
\end{tabular}

\begin{tabular}{|c|c|c|}
\hline \multirow{2}{*}{ Severity of Quick DASH Score } & \multicolumn{2}{|c|}{ Total } \\
\cline { 2 - 3 } & No. & \% \\
\hline 0-20 (near normal) & 0 & 0 \\
\hline 20-50 (mild) & 15 & 29.41 \\
\hline $50-80$ (moderate) & 30 & 62.74 \\
\hline$>80$ (severe) & 6 & 11.76 \\
\hline Table 3. Distribution of Severity of Patients according to \\
Quick DASH Score (n= 51) \\
\hline
\end{tabular}

\begin{tabular}{|c|c|c|c|c|}
\hline \multirow{2}{*}{ Mode of Onset } & \multicolumn{2}{|c|}{$\begin{array}{c}\text { Number of } \\
\text { Patients }\end{array}$} & \multirow{2}{*}{$\begin{array}{l}\text { Quick } \\
\text { DASH } \\
\text { Mean } \\
\text { Value }\end{array}$} & \multirow{2}{*}{$\begin{array}{c}\text { Quick } \\
\text { DASH } \\
\text { Standard } \\
\text { Deviation }\end{array}$} \\
\hline & Total & $\%$ & & \\
\hline Total & 51 & 100 & 61.35 & $\mathrm{SD}=20.5$ \\
\hline Post-traumatic injury & 12 & 23.5 & 83.25 & $\mathrm{SD}=13.13$ \\
\hline Non-traumatic patients & 39 & 76.47 & 57.41 & $\mathrm{SD}=14.65$ \\
\hline \multicolumn{5}{|c|}{$\begin{array}{l}\text { Table 4. Distribution according to Mode of } \\
\text { Onset and Quick DASH Score }(n=51)\end{array}$} \\
\hline
\end{tabular}

\begin{tabular}{|c|c|c|c|}
\hline $\begin{array}{c}\text { Electromyographic } \\
\text { Variable }\end{array}$ & \multicolumn{3}{|c|}{ Total } \\
\cline { 2 - 4 } & Present & Absent & $\%$ Positive \\
\hline $\begin{array}{c}\text { Voluntary muscle } \\
\text { contraction }\end{array}$ & 39 & $12^{*}$ & 76.47 \\
\hline Recruitment & 39 & $12^{*}$ & 76.47 \\
\hline Spontaneous potential & 51 & 0 & 100 \\
\hline \multicolumn{4}{|c|}{$\begin{array}{c}\text { Table 5. Distribution of Patients according to } \\
\text { Electromyographic Findings (n= 51) }\end{array}$} \\
\hline
\end{tabular}

*All patients had post-traumatic injury.

\section{DISCUSSION}

\section{Age Distribution}

Maximum number of patients were from age group twenty to forty years accounting for $64.7 \%$ of all patients. Mean age of studied patients was 36 years (SD, 11.7 years). Youngest patient was of 15 years old and eldest was of 55 years old. In our study reason for early involvement of neuropathy is because of the working habits of females and proneness of trauma in males. Most of the traumatic injuries are also seen in young age group justifying the preponderance of neuropathy in males of 20 - 30 years. There are a good percentage of patients above the 50 years of age. This is mainly because of causes like carpal tunnel syndrome and diabetic neuropathies. Mondelli et $\mathrm{al}^{3}$ found mean age of 55 years (range 13 - 97 years) in patients of carpal tunnel syndrome. Ahmed et $\mathrm{al}^{4}$ found that mean age of their patients was 32.7 years. This is comparable to our study. Tulipan et al 2 in their study found average age of 58.6 years (range $26-86$ years). This was dissimilar to our study, because Tulipan et $\mathrm{al}^{2}$ excluded traumatic injury patients from their study.

\section{Gender Distribution}

$68.62 \%$ of the patients were female with female-to-male ratio of 2.18: 1 . Tulipan et $\mathrm{al}^{2}$ in their study found similar incidence $(68 \%)$ of female preponderance. Mondelli et $\mathrm{al}^{3}$ also found 
higher sex specific incidence in females. Treaster et al ${ }^{5}$ found that majority of the studies done shows that women have significantly higher incidences of upper extremity musculoskeletal disorders than men. Higher number of females is due to preponderance of neuropathies in females, again probably due to their involvement in day-to-day fine activities. Females are used to doing all sorts of household and kitchen works. Number of males is higher in traumatic group owing to their vulnerability to accidents and adventures.

\section{Aetiological Agents or Mode of Onset}

Based on the mode of onset or aetiological agents, authors had classified the patients widely in two groups; traumatic and non-traumatic. Non-traumatic patients consisted of 39 patients including carpal tunnel syndrome, leprosy, schwannomas, diabetic neuropathy and various aetiologies. Traumatic injury patients included brachial plexus injury, posterior interosseous palsy, radial nerve, median nerve and ulnar nerve injuries. Trivedi et $\mathrm{al}^{1}$ in their study found that multiethnicity and multicultural population of India is exposed to various environmental and day-to-day factors, which adversely predisposes to neuropathies. Similar to our study, they identified causes of neuropathies as inflammatory neuropathy, leprous neuropathy and geographic and occupational distribution of adverse agents. They have not mentioned traumatic neuropathy in their list of causes. This was dissimilar to our study.

Carpal tunnel syndrome was one of the common nontraumatic aetiologies in our study. Roquelaure et $\mathrm{al}^{6}$ in their study identified that obesity and baseline psychological stress are strongly predictive of carpal tunnel syndrome. They also mentioned that a rapid finger movement is also a predictor of carpal tunnel syndrome. Strict control by superiors is negatively associated with disease. Spahn et al ${ }^{7}$ also found that prevalence of carpal tunnel is higher in working population than in general population. In their study, they mentioned it as occupational disease. Repetitions, chronic wrist flexion, powerful grip and chronic vibration load are associated with carpal tunnel syndrome. Shiri et al ${ }^{8}$ also mentioned association of carpal tunnel syndrome with work task involving forceful repetitive work and vibration.

\section{Quick DASH Score}

Disability assessment of patients was evaluated by quick DASH score. None of the patients had normal or near normal quick DASH score signifying that neuropathy was always disabling. There is no established benchmark for interpreting the scores. Authors empirically classified the score as normal or near normal, mild, moderate and severe.

a. Normal or near normal $=<20$

b. $\quad$ Mild $=20-50$

c. Moderate $=50-80$

d. Severe $=>80$

In the study of Novak CB et al, ${ }^{9}$ it was hypothesised that at least 6 months after trauma patients would have considerable disability and pain which can be predicted strongly by disabilities of the Arm, Shoulder and Hand (DASH) score. Kretschmer et al ${ }^{10}$ also mentioned about Ulm questionnaire that included categories of satisfaction, functionality, pain comorbidities and work. It was studied with DASH scores. It was found that despite high satisfaction rate, patients had considerable disability. Novak CB et al ${ }^{11}$ in their study evaluated the biomedical and psychosocial factors associated with disabilities following upper extremity trauma. They evaluated predictors of DASH score.

Ahmed-Labib et al ${ }^{4}$ evaluated the functional outcome and quality of life following brachial plexus injury using short form 36, DASH score, pain visual analog scale and an additional question for satisfaction. Hill BE et al ${ }^{12}$ in their clinimetric study attributed to ABILHAND and Disability of the Arm, Shoulder and Hand (DASH) for more than 50\% of the overall score to activities of the upper limb. DASH score showed some evidence of clinimetric properties of individual with peripheral nerve injuries.

Itsubo et $\mathrm{al}^{13}$ used Japanese Society for Surgery of the Hand Severity Score (CTSI-JSSH-SS) for disability evaluation. Atroshi et al ${ }^{14}$ mentioned a Swedish version of DASH questionnaire that is reliable and valid instrument for outcome measurement in upper extremity musculoskeletal conditions.

\section{Quick DASH Score Values}

Maximum number of patients (62.74\%) had score of $50-80$, which authors have written as of moderate severity. 29.41\% patients had mild disability of range $20-50$. Severe disability of score $>80$ was found in $11.76 \%$ of patients. Mean quick DASH score was 61.35 with standard deviation of 20.5. Mean DASH score in traumatic injury patients was of great severity, i.e. 83.25 with SD 13.13. Novak et $\mathrm{al}^{9}$ in their study of traumatic nerve injuries found mean DASH score of 52 (SD, 22 ) and this is of moderate severity as per our grading. This finding is dissimilar to our finding of severe score in traumatic injury patients. Novak et $\mathrm{al}^{9}$ also mentioned that body pain, age and nerve injuries were significant predictors of DASH score. Kretschmer et al ${ }^{10}$ also mentioned that mean DASH score in their study of disability after brachial plexus injury was 52 (SD, 13). This finding is also dissimilar to our study. Novak CB et al ${ }^{11}$ mentioned about predictors of DASH score in patients with nerve injury. They mentioned that DASH score is predicted by brachial plexus injury, older age, pain intensity, work status, time since injury, cold sensitivity and pain catastrophizing. We need to do further study based on those parameters to provide a realistic assessment. Mean quick DASH score in non-traumatic injury patients was of moderate severity, i.e. $57.41(\mathrm{SD}=14.65)$. This observation is because of the reason that traumatic injury patients succumb to neurotmesis which is more disabling than axonotmesis. Kretschmer et al ${ }^{10}$ mentioned the role of occupational retraining for patients with considerable disability.

Ahmed et $\mathrm{al}^{4}$ in their study on functional outcome of brachial plexus found no difference in DASH scores of supraand infra-clavicular injuries, but patients with root avulsion had worse DASH scores. We did not include details of nerve injury in our study. Hill et al ${ }^{12}$ recommended development of questionnaire that evaluates activity, body structure, body function and participation for clinimetric assessment of nerve injuries. Tulipan et $\mathrm{al}^{2}$ in their study correlated DASH scores with electrodiagnostic severity in patients of carpal tunnel syndrome. 


\section{Analysis of Electromyographic Parameters}

Authors included the electromyographic parameters with intention to differentiate that if the neuropathic pathology was neuropraxia, axonotmesis or neurotmesis. Authors purposefully excluded the nerve conduction study parameters like latency, amplitude and conduction velocity because in the study by Tulipan et $\mathrm{al}^{2}$ it was found that nerve conduction study parameter does not correlate well with patient-reported disability including DASH and Mental Component Summary (MCS-12) survey. Unlike our study Tulipan et $\mathrm{al}^{2}$ excluded traumatic injury patients from their studies. Itsubo et $\mathrm{al}^{13}$ in their study mentioned that no significant correlation is observed between Japanese versions of patient-oriented questionnaires and electrophysiological examinations in patients with carpal tunnel syndrome.

\section{Development of Spontaneous Muscle Potential}

It was observed in all the 51 muscle samples supplied by pathological nerve. This suggests that muscle unit is denervated for more than 6 weeks duration and this has allowed the Wallerian degeneration to set in the distal neuron. Denervated motor units become more excitable owing to physiological changes in ion permeability and potential difference across cell membrane leading to discharge of spontaneous potential. Thus, it can be inferred that all the neuropathic muscles had loss of axons suggestive of either axonotmesis or neurotmesis. Condition of neuropraxia can definitely be ruled out.

\section{Voluntary Muscle Contraction}

a. It was absent in 12 patients of traumatic aetiology suggesting that denervation of the sampled muscle unit was complete (neurotmesis). These sort of patient does not improve with conservative treatment and they require exploration of the nerve and microvascular coaptation of the cut ends either through end-to-end anastomosis or sural nerve graft. If it is not possible to identify and dissect the proximal stump as in case of root avulsion in brachial plexus injuries than nerve transfer procedures like intercostal nerve transfer, spinal accessory nerve transfer, phrenic nerve transfer or opposite C7 nerve transfer can be done to restore the nerve functioning. Quick DASH score obtained in traumatic nerve injury patient was of severe degree (Mean 83.25, SD=13.13) owing to complete denervation of the muscle unit.

b. Voluntary muscle contraction was obtainable in 39 nontraumatic neuropathy patients suggesting that denervation of muscle unit was not complete. Pathology expected in such conditions is axonotmesis. Usually axonotmesis is initially treated conservatively and if it does not improve then surgical intervention like decompression is done. E.g. Carpal tunnel release is done in cases of severe carpal tunnel syndrome. Quick DASH score obtained in such patients was of moderate severity (Mean 57.41, SD= 14.65).

\section{Recruitment Pattern}

It is another electromyographic parameter studied by authors. Whenever a subject is asked to contract a muscle and recording needle is kept in the muscle unit as happens during electromyographic study, it produces an action potential which is recorded by measuring device. Mild twitching of muscle generates small force at slower rate. Voluntary forceful muscle contraction results in recruitment of more and more muscle units and thereby resulting in full interference pattern.

In our study, we found that 12 traumatic injury neuropathy patients were not able to generate enough force to contract the muscle unit and this is again because of the fact that their muscle units were completely denervated (neurotmesis). On the contrary, the non-traumatic neuropathy patients were able to generate some or more force to record the recruitment pattern suggesting that denervation was not complete (axonotmesis).

\section{CONCLUSION}

Quick DASH score is an effective measurement tool for disability analysis in cases of peripheral neuropathies. Authors have empirically graded the quick DASH score as mild, moderate and severe depending on their values and it correlated well with the pathologies of neuropathies which are classified as neuropraxia, axonotmesis and neurotmesis. Electromyographic findings of voluntary muscle contraction, recruitment of muscle units and spontaneous potentials were supportive in such pathological differentiation. Authors concluded that traumatic neuropathies have electromyographic findings of neurotmesis resulting in severe quick DASH score unlike the non-traumatic neuropathies that have electromyographic findings of axonotmesis with moderate quick DASH score.

\section{REFERENCES}

[1] Trivedi S, Pandit A, Ganguly G, et al. Epidemiology of peripheral neuropathy: an Indian perspective. Ann Indian Acad Neurol 2017;20(3):173-84.

[2] Tulipan JE, Lutsky KF, Maltenfort MG, et al. Patientreported disability measures do not correlate with electrodiagnostic severity in carpal tunnel syndrome. Plast Reconstr Surg Glob Open 2017;5(8):e1440.

[3] Mondelli M, Giannini F, Giacchi M. Carpal tunnel syndrome incidence in a general population. Neurology 2002;58(2):289-94.

[4] Ahmed-Labib M, Golan JD, Jacques L. Functional outcome of brachial plexus reconstruction after trauma. Neurosurgery 2007;61(5):1016-22; discussion 1022-3.

[5] Treaster DE, Burr D. Gender differences in prevalence of upper extremity musculoskeletal disorders. Ergonomics 2004;47(5):495-526.

[6] Roquelaure Y, Mariel J, Dano C, et al. Prevalence, incidence and risk factors of carpal tunnel syndrome in a large footwear factory. Int J Occup Med Environ Health 2001;14(4):357-67.

[7] Spahn G, Wollny J, Hartmann B, et al. Metaanalysis for the evaluation of risk factors for carpal tunnel syndrome (CTS) Part II. Occupational risk factors. Z Orthop Unfall 2012;150(5):516-24.

[8] Shiri R, Miranda H, Heliövaara M, et al. Physical work load factors and carpal tunnel syndrome: a population-based study. Occup Environ Med 2009;66(6):368-73. 


\section{Jemds.com}

[9] Novak CB, Anastakis DJ, Beaton DE, et al. Patientreported outcome after peripheral nerve injury. J Hand Surg Am 2009;34(2):281-7.

[10] Kretschmer T, Ihle S, Antoniadis G, et al. Patient satisfaction and disability after brachial plexus surgery. Neurosurgery 2009;65(4 Suppl):A189-96.

[11] Novak CB, Anastakis DJ, Beaton DE, et al. Biomedical and psychosocial factors associated with disability after peripheral nerve injury. J Bone Joint Surg Am 2011;93(10):929-36.

[12] Hill BE, Williams G, Bialocerkowski AE. Clinimetric evaluation of questionnaires used to assess activity after traumatic brachial plexus injury in adults: a systematic review. Arch Phys Med Rehabil 2011;92(12):2082-9.
Original Research Article

[13] Itsubo $\mathrm{T}$, Uchiyama $\mathrm{S}$, Momose $\mathrm{T}$, et al. Electrophysiological responsiveness and quality of life (QuickDASH, CTSI) evaluation of surgically treated carpal tunnel syndrome. J Orthop Sci 2009;14(1):1723.

[14] Atroshi I, Gummesson C, Andersson B, et al. The disabilities of the arm, shoulder and hand (DASH) outcome questionnaire: reliability and validity of the Swedish version evaluated in 176 patients. Acta Orthop Scand 2000;71(6):613-8. 